\section{National publication bias}

SIR - The availability on disk of Current Contents makes possible a variety of statistical analyses of publications. The letter on national publication bias in scientific journals from E. Ernst and T. Kierbacher (Nature 352, 560; 1991) prompts me to report what may be called a 'language bias'. The number of publications originating from selected major countries was searched in issues 18-23 of Current Contents Life Science volume 34, covering 600 journals. The United States as such was omitted because the papers of that country appear under each state name, but three major states (California, New York and Texas) were searched for comparative purpose.

The table shows that in the period examined, the United Kingdom (sum of England, Scotland, Wales and Northern Ireland) produced approximately the same number of publications as Japan and West Germany combined. It is also seen that Canada produced approximately as many publications as West Germany.

One would expect that countries with comparable gross national products (GNP) per capita would produce a similar number of publications per head (see table). The differences between the countries became even more striking: the United Kingdom produced as many papers per capita as Japan, West Germany and France together. Interestingly, the countries (or states) producing the most publications per capita were English-speaking countries (or with a majority of native English-speaking inhabitants). The only exception is Sweden.

It is suggested that this bias originates from the fact that the vast majority of the publications in the scientific literature are in English (the excellent English of Swedes is well known). The usefulness of a common language for science is not questioned, and English has proved

\begin{tabular}{|c|c|c|}
\hline \multicolumn{3}{|c|}{$\begin{array}{l}\text { PUBLICATIONS IN SELECTED COUNTRIES OR } \\
\text { STATES }\end{array}$} \\
\hline $\begin{array}{l}\text { Country } \\
\text { (or state) }\end{array}$ & $\begin{array}{l}\text { Total number } \\
\text { of publications }\end{array}$ & $\begin{array}{l}\text { Publications } \\
\text { per million } \\
\text { inhabitants }\end{array}$ \\
\hline California & 1274 & 62.1 \\
\hline New York & 858 & 47.1 \\
\hline Texas & 488 & 43.5 \\
\hline UK & 2268 & 40.5 \\
\hline Canada & 895 & 38.9 \\
\hline Sweden & 315 & 38.0 \\
\hline Australia & 440 & 31.0 \\
\hline France & 887 & 16.6 \\
\hline West German & 901 & 11.5 \\
\hline Japan & 1311 & 11.4 \\
\hline Italy & 544 & 9.6 \\
\hline
\end{tabular}

Found in Vol. 34 issues 18-23 of Current Contents Life Science (600 journals). to be that. But writing in English can be a considerable burden to those not fluent in that language, which could partly explain the bias (science policies and evaluations systems are certainly contributing too). In addition, the bias described above has certainly some other effects. For example, because publications have to be written in good English, the editorial boards of many international high impact journals are strongly dominated by scientists from Englishspeaking countries. Another example is with the evaluation of research groups from different countries when competing for international grants (for example in the European Communities).

It would be interesting to examine the average impact of publications from English vs. non-English-speaking countries to see if the bias persists.

\section{Centre de Recherches sur les}

Macromolécules Végétales,

CNRS, BP $53 X$,

F-38041 Grenoble, France

\section{Tissue shortage}

SIR - The lack of human tissue for research and education, a problem again identified by Christopher Anderson's report "Beating the tissue shortage" ( $\mathrm{Na}$ ture 351, 195;1991), has prompted animal welfare organizations in Britain and the United States to launch the Humane Research Donor Card (HRDC), with carriers requesting that "after my death any part of my body be used for medical and scientific research". The HRDC does not preclude people from also becoming donors for transplantation, and they can carry both types of card.

The card is an initiative of animal protection groups because human tissue is very much a neglected alternative to laboratory animals. In pharmacology for instance, the use of human material is still the exception rather than the rule, despite the limited relevance of most animal tissue studies ${ }^{1,2}$. In fact, analysis of papers presented at the April 1990 meeting of the British Pharmacology Society indicated that only a small proportion of experiments using isolated tissues employed material of human origin - 84 per cent used tissue from animals, mainly rats and guinea pigs.

Since February 1991, when the British group Animal Aid first launched the HRDC, public response has been overwhelmingly positive, with more than 60,000 cards already distributed, indicating a genuine desire to help both medical science and animals.

Many scientists have also welcomed the scheme $\mathrm{e}^{3}$ and not only for humane reasons: work with human tissues overcomes the problem of species variation and produces results directly relevant to people ${ }^{1,4-6}$.

Nevertheless, to achieve its full potential, there needs to be well co-ordinated systems of tissue storage, with hospitals and research institutions carrying a list of intended donors, thereby reducing the chance of tissues going to waste. If people carry the HRDC and inform relatives of their wishes, the problems encountered in Philadelphia will be avoided.

\section{Banner Cross Road,}

ROBERT SHARPE

\section{Ecclesall,}

Sheffield S11 9HO,

South Yorkshire, UK

1. Trends pharm. Science 8, 289-290 (1987).

2. Mülier-Schweinitzer, E. Trends pharm. Science 9, 221 223 (1988)

3. Outrage, April/May, June/July, August/September (1991) 4. McCormick. D.A. Trends pharm. Science 11, 53-56 (1990).

5.Powell, T. et al. Br. med. J.283, 1013-1014 (1981).

6. Yoshitomi, S. et al. in Vitro cell. dev. Biol. 23, 55 (1987)

\section{Designer data}

SIR - Your issue of 26 September (Nature 353, 294; 1991) illustrates a 1989 West German stamp showing a population pyramid for the German population for the year "1989" and a projected population pyramid for the year 2000 . These two pyramids are incompatible, because, although they are ostensibly based on populations 11 years apart, scrutiny shows that they are actually 15 years apart (for example, the peaks at age 20, 45 and 55 in "1989" correspond to ages 35,60 and 70 in 2000). Which then is correct? The two conspicuous troughs in the "1989" distribution, at ages 40 and 67 , seemingly result from the birth cohorts of 1949 and 1922 . It is more likely that this is the pyramid for 1985 , 15 years before 2000 , so that the two troughs correspond to cohorts with depressed birth rates at the ends of two world wars, in 1918 and 1945.

I conjecture that the stamp's designer had been supplied with demographic data for 1985 , probably the most recent year for which accurate statistics were available. Knowing that the stamp was to be issued in 1989 , to commemorate the centenary of the social security system, the designer changed the date (but not the data) to correspond to 1989 .

Scientific data are rarely printed on stamps; when they are, then aesthetics should be less important than accuracy.

Department of Psychology,

I. C. MCMANUS*

University of Waterloo,

Waterloo, Ontario N2L 3G1, Canada

*Permanent address: Department of Psychology, University College London, Gower Street, London WC1E 6BT, UK 